\title{
A QUANTUM MEASUREMENT APPROACH TO TUNNELLING
}


This page is intentionally left blank 


\title{
A OUANTUM MEASUREMENT APPROACH TO TUNNELLING
}

\section{Dilip K Roy}

\author{
Department of Physics \\ Indian Institute of Technology, Delhi, \\ Hauz Khas, New Delhi 110016, \\ India
}




\section{Published by}

World Scientific Publishing Co. Pte. Ltd.

P O Box 128, Farrer Road, Singapore 9128

USA office: Suite 1B, 1060 Main Street, River Edge, NJ 07661

UK office: 73 Lynton Mead, Totteridge, London N20 8DH

\section{A QUANTUM MEASUREMENT APPROACH TO TUNNELLING}

Copyright $@ 1993$ by World Scientific Publishing Co. Pte. Ltd.

All rights reserved. This book, or parts thereof, may not be reproduced in any form or by any means, electronic or mechanical, including photocopying, recording or any information storage and retrieval system now known or to be invented, without written permission from the Publisher.

ISBN $981-02-1223-2$

For copying of material in this volume, please pay a copying fee through the Copyright Clearance Centre, Inc., 27 Congress Street, Salem, MA 01970.

Printed in Singapore. 


\section{PREFACE}

By now quantum mechanical tunnelling has established itself as one of the important processes of quantum transport. Its theoretical basis appeared to emerge as one of the immediate consequences of wave mechanics. But, of late, the former came under some criticism due to its failure in explaining several wellestablished results of solid state tunnelling. The work presented here is concerned with the development of a new theoretical basis for the explanation of the tunnel effect on the ideas of quantum measurement and observations.

A matter wave is able to propagate by virtue of combined oscillations in position and time spaces. Each type of oscillation feeds the requisite energy for the other's maintenance. During its propagation through the position space its motion could easily be hampered by an obstacle placed in its path. In such a case, oscillations occurring in the time space undergo scattering in the energy space. Its net result is to introduce a spread in the energy value which becomes an observable quantity when the interaction of the matter wave with the barrier is over (or when a quantum of action is realized). Such a practice is well-known as "quantum measurement". The associated object which disturbs the wave motion is however known as an "apparatus". It may thus appear that the very attempt to detect matter waves in the position space may give rise to the generation of a wave packet. The latter is responsible for subsequent corpuscular behavior of matter. 
The quantum mechanical tunnelling of particles across potential barriers has been characterized here based on such ideas. The barrier has been treated to behave as an energy measuring apparatus for the incident electrons because it is capable of arresting matter wave oscillations in the position space momentarily. The wave oscillations in the time space however finds the barrier region as behaving like an energy slit. They therefore undergo diffraction effects through it, generating a continuous distribution in their energy within a range as determined by the barrier height. During scattering they are however constrained to exist within the barrier till their complete evolution. The latter may therefore be taken to function as a die to cast a wave packet. The position and the energy uncertainties of the generated wave packets are respectively determined by the height and the width of the potential barrier. The wave packet emerges out of the barrier after its complete evolution. This recurs with every wavelength of the incident wave operating upon the barrier.

The different tunnelling parameters are evaluated on the above-mentioned theoretical considerations. The tunnelling time was thus found to be the time of evolution of a wave packet. During that period the electron probability density within the barrier grows. After growth a tunnelling current is observable at the transmitted end.

The previous work in this area has already been published by the author in the form of two research monographs. The first one entitled, Tunnelling and Negative Resistance Phenomena in Semiconductors was published by Pergamon Press, Oxford, England in 1977. To incorporate various other types of tunnelling including Josephson effect the second book titled Quantum $\mathrm{Me}$ chanical Tunnelling and its Applications was published by World Scientific Publishing Company, Singapore in 1986. The present work however is concerned with the development of a generalized theory of quantum mechanical tunnelling only to be applicable to problems of general interest. This book is primarily intended 
for students of Physics interested in quantum mechanical tunnelling.

I received support from various quarters while writing this book. Special thanks are due to my colleagues Professors S. C. Mathur, A. K. Ghatak, K. P. Jain, R. G. Mendiratta and P. K. C. Pillai for providing me valuable encouragement while preparing the manuscript. At the end, I must put on record my sincere appreciation for the patience and understanding shown by my wife and children without which the writing of this book would have been impossible!

IIT Delhi, New Delhi

DILIP K. ROY India 
This page is intentionally left blank 


\section{CONTENTS}

Preface $\ldots \ldots \ldots \ldots \ldots \ldots \ldots \ldots \ldots \ldots \ldots \ldots \ldots \ldots$

Chapter 1 CONVENTIONAL ANALYSIS OF THE TUNNEL EFFECT

1.1. Introduction $\ldots \ldots \ldots \ldots \ldots \ldots \ldots \ldots \ldots \ldots \ldots$

1.2. Conventional formulations $\ldots \ldots \ldots \ldots \ldots \ldots \ldots \ldots$

1.2.1. Time-independent approach ........... 3

1.2.2. Time-dependent perturbation approach ..... 19

1.2.3. Equivalence of time-independent and

time-dependent perturbation approaches .... 22

1.3. Analysis of physical problems on conventional theory . 24

1.3.1. Alpha decay problem ............... 24

1.3.2. Field emission from cold metals . . . . . . . . 27

1.3.3. Tunnelling in solid-state junctions ........ 32

1.3.4. Scanning Tunnelling Microscope (STM) .... . 37

1.4. Inadequacies of conventional approaches ........ 38

1.5. Summary ...................... 40

Chapter 2 THEORY OF QUANTUM MEASUREMENT AND OBSERVATIONS

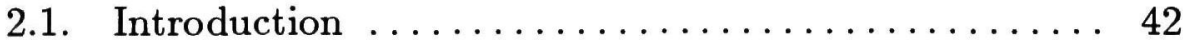

2.2. Evolution of a wave packet .............. 47

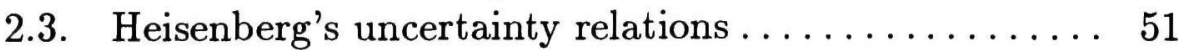

2.4. Analysis of quantum measurement problems........ 54

2.5. Summary ...................... 60 
Chapter 3 TUNNELLING FROM THE VIEWPOINT OF QUANTUM MEASUREMENT

3.1. Introduction $\ldots \ldots \ldots \ldots \ldots \ldots \ldots \ldots \ldots \ldots \ldots \ldots \ldots \ldots$

3.2. Tunnelling time and its experimental measurement ... 65

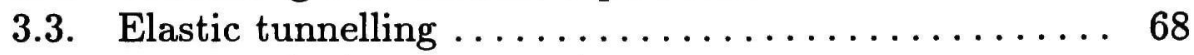

3.3.1. The barrier Hamiltonian . . . . . . . . . 69

3.3.2. Barrier wave function .............. 70

3.3.3. Tunnelling probability $\ldots \ldots \ldots \ldots \ldots \ldots \ldots 72$

3.3.4. Tunnelling current density ............ 84

3.3.5. Applications to solid-state tunnel junctions ... 88

3.3.6. Miscellaneous other applications . ....... 93

3.4. Inelastic tunnelling .................. 96

3.4.1. Barrier Hamiltonian and wave function ..... 97

3.4.2. Tunnelling probability and current density .. 103

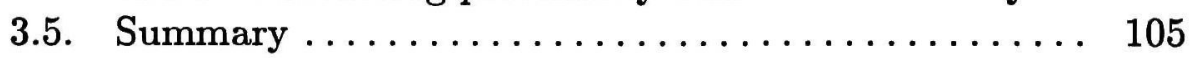

References ........................... 108

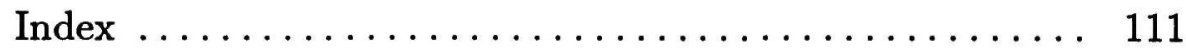

